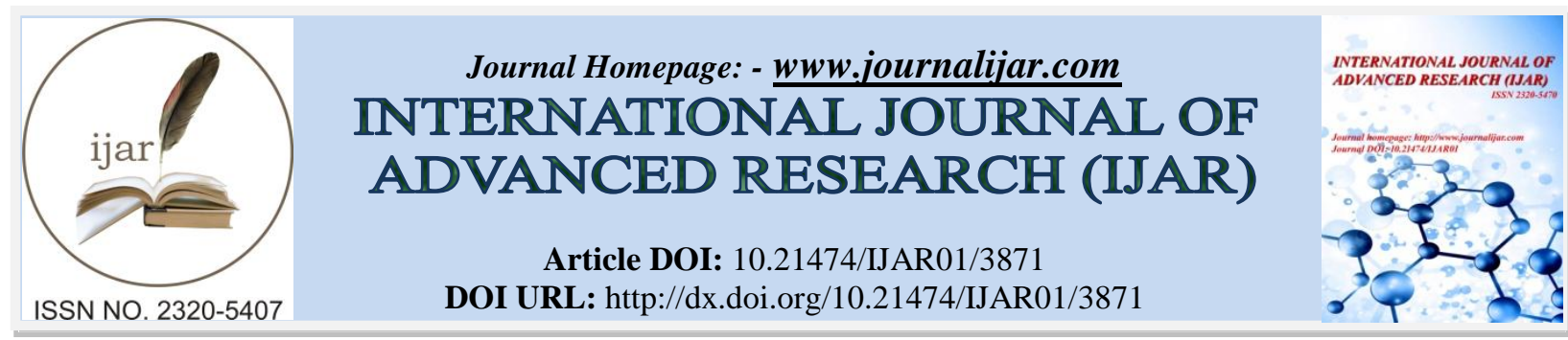

RESEARCH ARTICLE

\title{
DETERMINING THE EFFECT OF AFLATOXIN B1 USING HEMOGLOBIN OF HUMAN BLOOD AS INTERACTING MEDIUM BY CALCULATION OF COLLISION ENERGY.
}

\author{
Bhadra Preetha ${ }^{1}$, Das Mukhopadhyay Chitrangada ${ }^{2}$ and "Mukherjee Sampad ${ }^{3}$. \\ 1. Junior Research Fellow,Department of Physics, Indian Institute of Engineering Science and Technology. \\ 2. Centre for Healthcare Science and Technology, Indian Institute of Engineering Science and Technology. \\ 3. Associate Professor, Department of Physics, Indian Institute of Engineering Science and Technology.
}

\section{Manuscript Info}

Received: 12 February 2017

Final Accepted: 07 March 2017

Published: April 2017

Key words:-

Aflatoxin B1, Red Blood Corpuscles,

SEM, UV-Vis, FTIR, Collision Energy

\section{Manuscript History}

\begin{abstract}
The objective of this study concerns whether there is any biochemical changes of the Red Blood Corpuscles (RBC) of human blood by using different concentrations (in micro molar) of Aflatoxin B1 (AflB1) and to determine the changes using the collision energy. RBC from the human blood was treated by AflB1at different time interval and the respective samples have been characterized by optical microscope followed by UV-Vis spectrophotometer and Fourier Transform Infra Red spectroscopy (FTIR). From the optical microscope data it has been noticed that the structure of the RBC is altered which is supported by the scanning electron microscope (SEM) pronouncedly. In the results studied by FTIR, some unconventional peaks have found and from these data we conclude about the typical bonding nature between the atoms involving in $\mathrm{Hb}$ and AflB1 chemical structure. The bonding of the newly formed structure is quite similar to that of the Aflatoxin G1 (AflG1) and after a period of time again the structure of the AflB1 (which initially added to the sample) returns back. According to our study the phenomena relating to the returning of the AflB1 structure is not only a factor of concentration of AflB1 added but also depends upon the duration of biochemical interaction of AflB1 with $\mathrm{Hb}$. The change in collision energy due to structural deformation of Aflatoxin can easily be calculated from FTIR spectra data.
\end{abstract}

Copy Right, IJAR, 2017,. All rights reserved.

\section{Introduction:-}

Low exposures to the toxic materials are the huge threat to the living world. RBCs are found to be the best clinical bed to observe the toxicity of any material. Some metal like lead, cadmium, mercury and arsenic are the prime toxic metals affecting the human body as well as other living beings. They mainly acts as the Hydroxyl $\left(\mathrm{OH}^{-}\right)$, super oxide $\left(\mathrm{O}_{2}{ }^{-}\right)$and hydrogen peroxide $\left(\mathrm{H}_{2} \mathrm{O}_{2}\right)$ forms for the toxicity [1] though some metal oxide has found to be effective in some diseases causes by parasites, fungi [2] etc. The toxic materials have the direct interaction with the protein synthesis of the body [3].The textile dye which is found as a threat for the water lives as it mainly acts on the oxygen supply to the lives and some changes have also been found in the blood component of them [4]. It can be easily established from the extensive studies on the effect of different toxic materials on the lives mainly on the blood of any living being. As the distribution of every essential molecules like enzymes, hormones etc. are carried by the blood, there should have some conformational modification of the blood [5-9]. The cytotoxic elements also carried 
by the bloodand for the effects of them are concluded based on the blood test report. Free radical generation may have some contribution on these types of effect in the blood. There may be the contribution of other charged particles carried by blood like $\mathrm{Na}^{+}, \mathrm{K}^{+}$, and group of the halogens and other non metals [10]. The conformational changes of RBCs mainly occur due to the presence of iron and the Heme protein which take part in the interaction with the foreign materials. As the mature RBCs are anucleated [11] they are unable to protein synthesis and hence the conclusions have been made that the virus cannot invade them [12].

Aflatoxins are found to be a potent cytotoxic compond for the food and the feed product, produced by the Aspergillusflavus and Aspergillusparasiticus [13] found in the corn, peanuts, and other crops and grains [14] and also in the animal feed [15]. Aflatoxin B1 (AflB1) has found to be the most hazardous among all mycotoxin in the group of Aflatoxin G1, G2, B1, B2 and there is no threshold concentration for its toxic effect and also a potent carcinogen for the Hepatocelular Cancer i.e liver cancer [16]. It is also establishedthat Aflatoxin (in any form) has the contribution for the causes of embryotoxicity [17], genotoxicity[18], teratogenicity[19] etc in animals. Epithelial exposure to the AflB1 can lead to the major health risk [20]. Most of the studies so far have shown the effect of AflB1 in protein and DNA levels. FTIR analysis is agood tool for the study of effect of AflB1 on different food and feed products [21].

RBCs are consisting of hemoglobin which is a complex protein containing heme groups whose iron (Fe) atoms are responsible for the binding with other atoms [22]. RBC are anucleated i.e. it lacks a nucleus [23,24] and are a well frame to work with for the studies of the interaction and the bond formation of AflB1 with the metalloproteins contain in RBCs. The possibility of these interactions might explain with the tertiary structure of proteins, mainly in heme proteins where the electronegative group is the back bone of the hemoglobin [25-32]. Some experimental studies showed that there are various mechanismstocollect the iron from the environment in useful form like insoluble ferric iron $(\mathrm{Fe}+3)$ to the soluble ferrous form $(\mathrm{Fe}+2)[31,32]$.

Analysis for aflatoxin in foods is a very important practice to ensure food quality and safety and to eliminate the risk of consuming contaminated foods. Hence, being able to sensitive detection of the affecting bond between this mycotoxin present in foods and drinks and the human body is a priority to comply with the legislative limits set by food authorities worldwide. This may lead us for the study of detoxification of AflB1 in human cells. Main objective of our study is to characterize the bonds between two i.eHb and AflB1 and to determine the transition of the state of Fe in respect to the bond found in the UV-Vis and FTIR so far which helps the researchers to get some idea about the nature of the bond and find the way out to revive the affected samples in a good conditions.

\section{Materials and Methods:-}

Materials: we have used the chemicals PBS buffer, $\mathrm{NaCl}, 1 \%$ Methanol as a solvent ,AflB1 from Sigma -Aldrich. Distilled water and isolated the RBC with the standard Protocol [33].

\section{RBC isolation:-}

First draw the whole blood by a syringe and centrifuge whole blood at 500xg for 10 min at 4 degrees Aspirate supernatant (plasma) and add cell wash buffer to erythrocyte pellet. Centrifuge (Eppendorf) erythrocytes at 500xg for $10 \mathrm{~min}$ at 4 degrees C. Aspirate supernatant and add cell wash buffer to erythrocyte pellet. Repeat steps 3 and 4 two more times for a total of 3 washes of the erythrocytes.

\section{NaCl solution Preparation:-}

$4.5 \mathrm{~g} \mathrm{NaCl}$ ( $\mathrm{mw} 58.44$ ) is mixed with350 $\mathrm{ml}$ deionized or distilled water in clean container then the water was added to bring total solution volume to $500 \mathrm{ml}$.

\section{Different concentration of AflB1 solution preparation:-}

A stock solution of $20 \mu \mathrm{M}$ concentrations was prepared by dissolving $5 \mathrm{mg}$ Aflatoxin in $8 \mathrm{ml} \mathrm{Methanol} \mathrm{(1 \% ).} \mathrm{This}$ particular concentration of methanol has found to be harmless on the cells [34] and solution has prepared of three different concentration $10 \mu \mathrm{M}, 5 \mu \mathrm{M}, 2.5 \mu \mathrm{M}$

\section{Methods:- \\ Treatment with AflB1:-}

Isolated RBCs are then treated with different concentration of AflB1 and Incubated for different time frame like, 3 hours, 6hours, 12 hours, 24 hours, 48 hour in a $\mathrm{CO}_{2}$ incubator. 


\section{Microscopic analysis:-}

After incubation of different time frame the RBCs are examined under the microscope (Nikon Eclipse Ti (cursive) inverted microscope) and the pictures are taken in $40 \mathrm{X}$ magnification.

\section{SEM:-}

A field emission scanning electron microscopy (FE-SEM) study was performed to characterize and determine the morphology of the treated RBCs. A thin layered RBC sample was coated with a carbon under high vacuum and examined by FE-SEM (Carl Zeiss Supra SEM instrument).

\section{UV-Vis analysis:-}

After the incubation period the RBCs are treated with the $0.9 \% \mathrm{NaCl}$, a hypertonic solution and again incubated for 1 hour. After this, the solution was centrifuged in $6000 \mathrm{rpm}$ for 6 minutes and the supernatant is collected and analyzed in UV-Vis spectroscope (JASCO).

\section{FTIR:-}

After each incubation $\mathrm{KBr}$ plate is prepared with the solution and the FTIR (JASCO) analysis is done.

\section{Result and Discussion:-}

\section{SEM Analysis:-}

Fig:1: shows the images ofFE-SEM from which it is clear that there is a change in size as well as the shape of RBC which occur definitely for the biochemical interaction of $\mathrm{Hb}$ with the added AflB1.

\section{SEM Analysis:}

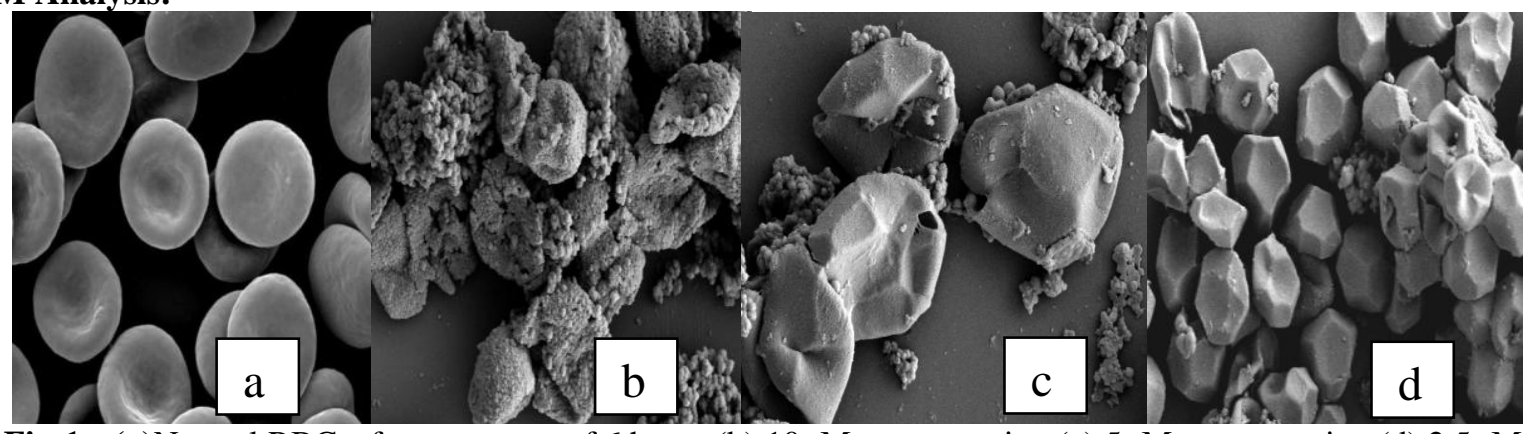

Fig:1:- (a)Normal RBC, after treatment of 6 hours (b) $10 \mu \mathrm{M}$ concentration,(c) $5 \mu \mathrm{M}$ concentration,(d) $2.5 \mu \mathrm{M}$ concentration

\section{UV-Vis analysis:-}

The study of UV-Vis shows a broad peak on the edge of red (of the visible spectrum) which is obvious and the results of UV-Vis spectroscopy ensure that the changes in these biochemical reactions are dominated by the structural change and this can be explained properly by the FTIR analysis which are discussed below. The analytical graph has shown in Fig 2 which has shown a gradual decrement of peaks with the decrement of the concentration of AflB1 (Fig 2: (a), (b), (c)). Most of the peaks were near to the IR range in Fig 2.

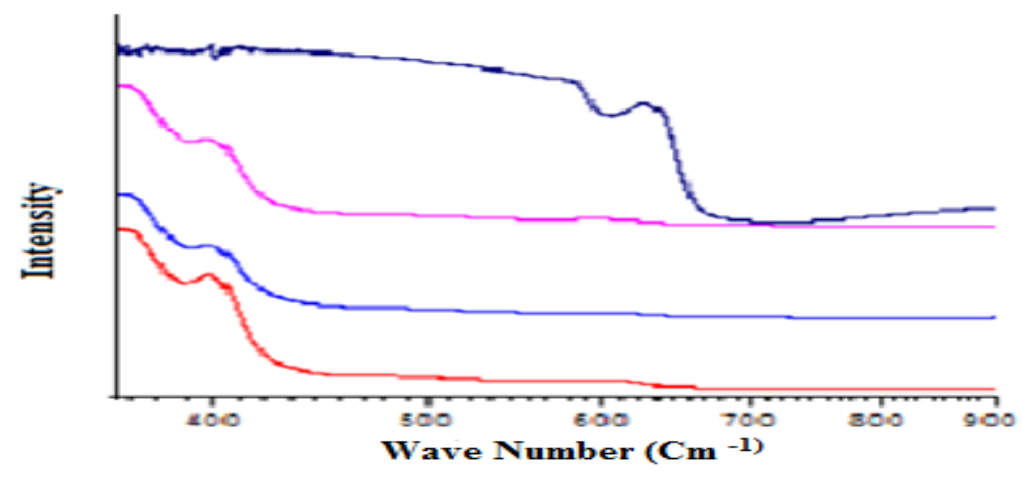



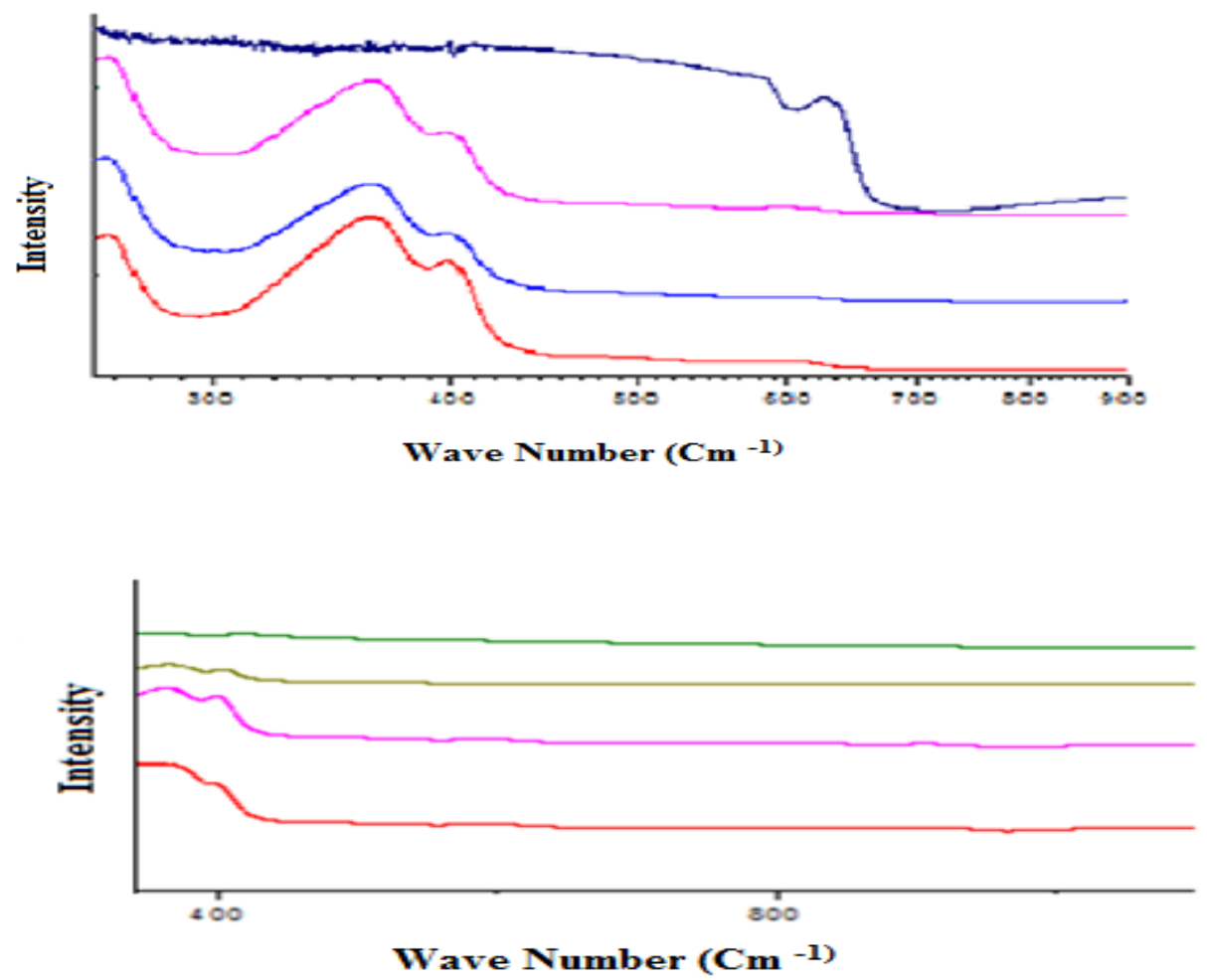

Fig 2:-

(a) UV-Vis Result for $10 \mu \mathrm{M}$ concentration in different time frame (3hr, $6 \mathrm{hr}, 12 \mathrm{hr}, 24 \mathrm{hr}$ )(b)UV-Vis Result for $5 \mu \mathrm{M}$ concentration in different time frame $(3 \mathrm{hr}, 6 \mathrm{hr}, 12 \mathrm{hr}, 24 \mathrm{hr})$

(c) UV-Vis Result for $2.5 \mu \mathrm{M}$ concentration in different time frame $(3 \mathrm{hr}, 6 \mathrm{hr}, 12 \mathrm{hr}, 24 \mathrm{hr})$

\section{FTIR analysis:-}

The unconventional peak has found along with the suppression of characteristics peaks of AflB1 in those samples which are incubated for 6 hours for the concentrations of $10 \mu \mathrm{M}$ and $5 \mu \mathrm{M}$ both and these peaks are surprisingly disappeared at 24 hours of incubation. But in the case of $2.5 \mu \mathrm{M}$ the coexistence of unconventional peaks and characteristics peaks of AflB1 occur for different times of incubation of the study. From these results it can be concluded that the free radical of the $\mathrm{Hb}$ has changed the structure of the AflB1 and again after certain time the structure revived. So far the molecular structure of different forms of Aflatoxins, the conclusions have been made that the unconventional peaks are due to the formation of AflG1 from AflB1 and as the review is concerned [35] the scale of toxicity of AflB1 is more than that of AflG1 and this is a good achievement of this work so far reported. One more important findings of this study is that the change in internal energy (preferably known as collision energy) of the structure of AflB1 to AflG1 calculated based on the peaks found in our FTIR data isfairly in agreement with the data reported by ref 35 who are estimated the collision energy value from another experiments like mass spectrographs etc. 

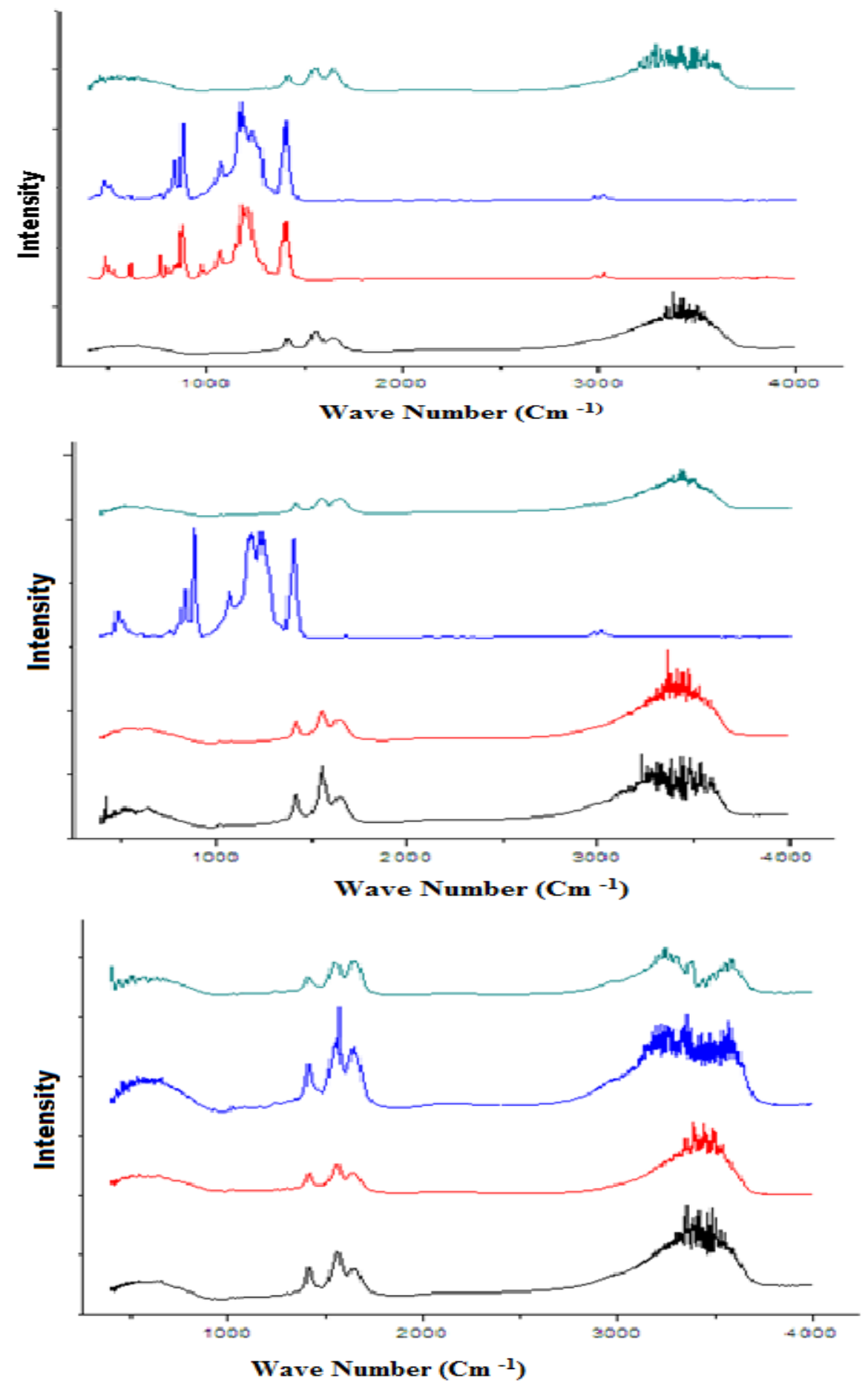

Fig:3:- FTIR results of (a) $10 \mu \mathrm{M}$ concentration in different time frame (3hr, $6 \mathrm{hr}, 12 \mathrm{hr}, 24 \mathrm{hr}$ ) (b) $5 \mu \mathrm{M}$ concentration in different time frame $(3 \mathrm{hr}, 6 \mathrm{hr}, 12 \mathrm{hr}, 24 \mathrm{hr})$ (c) $2.5 \mu \mathrm{M}$ concentration in different time frame $(3 \mathrm{hr}, 6 \mathrm{hr}, 12 \mathrm{hr}, 24 \mathrm{hr}$ )

\section{Conclusion:-}

An important conclusion can be made that FTIR is a very good and appropriate technique to estimate about the change in collision energy for any structural change of these types of toxic materials than the other methods and so far our review is concerned this is the first ever reported. 


\section{Acknowledgement:-}

We want to acknowledge the Department of BioTechnology (Govt. of India) for the financial support. We would also want to thank you Centre of Excellence for Green Energy and Sensor Systems, IIEST, Shibpur for running of the characterization of the material.

\section{References:-}

1. Ercal, N.; Gurer-Orhan, H.; Aykin-Burns, N. Toxic Metals and Oxidative Stress Part I: Mechanisms Involved in Metal-induced Oxidative Damage. Current Topics in Medicinal Chemistry, Volume 1, Number 6.December 2001, pp. 529-539(11).

2. Metal ions and biological system by Helmut Sigal, University of Basel.

3. David Quig, Ph.D.Cysteine Metabolism and Metal Toxicity. Altern Med Rev 1998;3(4):262-270.

4. Pratima Soni1, Subhasini Sharma, Shweta Sharma, Suresh Kumar and K. P. Sharma. A comparative study on the toxic effects of textile dye wastewaters (untreated and treated) on mortality and RBC of a freshwater fish Gambusiaaffinis (Baird and Gerard).Journal of Environmental Biology October 2006, 27(4) 623-628 (2006).

5. Mortensen SP, Dawson EA, Yoshiga CC, et al. (July 2005). "Limitations to systemic and locomotor limb muscle oxygen delivery and uptake during maximal exercise in humans".J. Physiol. (Lond.).PMC 1464731. PMID 15860533.

6. The 'St George' Guide To Pulmonary Artery Catheterisation

7. Oxygen Carriage in Blood - High Altitude

8. Martini, Frederic; et al. (2007). Anatomy and Physiology. Rex Bookstore, Inc. p. 643. ISBN 9789712348075.

9. Vander's Human Physiology reported similar numbers: $60 \%$ carried as bicarbonate, $30 \%$ bound to hemoglobin as carbaminohemoglobin, and $10 \%$ physically dissolved. Widmaier, Eric P.; Raff, Hershel; Strang, Kevin T. (2003). Vander's Human Physiology (9th ed.). McGraw-Hill Education. p. 493 (ch. Respiratory physiology $\S$ Transport of carbon dioxide in blood). ISBN 0-07-288074-0

10. Yuan Z, Cai T, Tian J, Ivanov AV, Giovannucci DR, Xie Z (September 2005). "Na/K-ATPase tethers phospholipase $\mathrm{C}$ and IP3 receptor into a calcium-regulatory complex". Molecular Biology of the Cell. PMC 1196317 PMID 15975899

11. Galvano F., Ritieni A., Piva G., Pietri A. Mycotoxins in the human food chain. In: Diaz D.E., editor. The Mycotoxin Blue Book. Nottingham University Press; Nottingham, UK: 2005. pp. 187-224

12. Zimmer, Carl (2007-03-27). "Scientists Explore Ways to Lure Viruses to Their Death". The New York Times. Retrieved 2013-03-26.

13. Rania M. Azab; Wael M. Tawakkol; Abdel-Rahman M. Hamad; Mohamed K. Abou-Elmagd; Hassan M. ElAgrab and Mohamed K. Refai (2005). Detection and estimation of aflatoxin B1 in feeds and its biodegradation by bacteria and fungi. Egyptian Journal of Natural Toxins 2: 39-56.

14. Ilic, Z., Crawford, D., et al. (2010). Glutathione-S-transferase A3 knockout mice are sensitive to acute cytotoxic and genotoxic effects of aflatoxin B1. ToxicolApplPharmacol 242: 241-246.

15. E. Sur \& I. Celİk (2003). Effects of aflatoxin B1 on the development of the bursa of Fabricius and blood lymphocyte acid phosphatase of the chicken. British Poultry Science 44(4): 558-566. doi: 10.1080/00071660310001618352

16. Gursoy-Yuzugullu O, Yuzugullu H, Yilmaz M, Ozturk M (2011). Aflatoxin genotoxicity is associated with a defective DNA damage response bypassing p53 activation. Liver Int. 31(4): 561-71. doi: 10.1111/j.14783231.2011.02474.x

17. P.B. Wangikar, P. Dwivedi , N. Sinha, A.K. Sharma, A.G. Telang (2005). Effects of aflatoxin B1 on embryo fetal development in rabbits. Food and Chemical Toxicology 43(4): 607-615. doi:10.1016/j.fct.2005.01.004

18. Boonen, Jente; Malysheva, Svetlana V.; Taevernier, Lien; Diana Di Mavungu, José; De Saeger, Sarah; De Spiegeleer, Bart (2012). "Human skin penetration of selected model mycotoxins". Toxicology. 301 (1-3): 2132. doi:10.1016/j.tox.2012.06.012. PMID 22749975

19. M.E.S. Mirghania, Y.B. CheMana,*, S. Jinapb, B.S. Baharina, and J. Bakara. (2001) A New Method for Determining Aflatoxins in Groundnut and groundnut Cake Using Fourier Transform Infrared Spectroscopy with Attenuated Total Reflectance. JAOCS, Vol. 78, no. 10

20. Maton, Anthea; Jean Hopkins; Charles William McLaughlin; Susan Johnson; MaryannaQuon Warner; David LaHart; Jill D. Wright (1993). Human Biology and Health. Englewood Cliffs, New Jersey, USA: Prentice Hall. ISBN 0-13-981176-1

21. Cohen, W. D. (1982). "The cytomorphic system of anucleate non-mammalian erythrocytes". Protoplasma. 113: 23. doi:10.1007/BF01283036. 
22. Jump up^ Wingstrand KG (1956). "Non-nucleated erythrocytes in a teleostean fish Maurolicusmülleri (Gmelin)". Zeitschriftfür Zellforschung und Mikroskopische Anatomie. 45 (2): 195200. doi:10.1007/BF00338830 (inactive 2016-08-07). PMID 13402080

23. Blumberg, W. E. \&Peisach, J. (1971) Adv. Chem. Ser. 100,271-291.

24. Peisach, J., Blumberg, W. E. \& Adler, A. (1973) Ann. N. Y. Acad.Sci. 206, 310-326.

25. Peisach, J. (1975) Ann. N. Y. Acad. Sci. 244, 187-202.

26. Peisach, J. \& Mims, W. B. (1977) Biochemistry 16, 2795-2799.

27. Walker, F. A., Lo, M.-W. \&Ree, M. T. (1976) J. Am. Chem. Soc.98,5552-5560.

28. Satterlee, J. D., LaMar, G. N. \& Frye, J. S. (1976) J. Am. Chem.Soc. 98,7275-7282.

29. Metzler, D. E. (1977) Biochemistry, The Chemical Reactions of Living Cells (Academic, New York), pp. 566567.

30. Nappa, M., Valentine, J. S. \& Snyder, P. A. (1977) J. Am. Chem.Soc. 99,5799-5800.

31. Guerinot ML. Microbial iron transport. Annu Rev Microbiol. 1994;48:743-72

32. Askwith C, Kaplan J. Iron and copper transport in yeast and its relevance to human disease. Trends Biochem Sci. 1998;23:135-8.

33. Hanson MS, Stephenson AH, Bowles EA et al. Phosphodiesterase 3 is present in rabbit and human erythrocytes and its inhibition potentiates iloprost-induced increases in cAMP. Am.J.Physiol Heart Circ.Physiol 2008;295:H786-H793.

34. Melda Sonmez1, HuseyinYavuz Ince1, Ozlem Yalcin1, Vladimir Ajdžanović2, Ivan Spasojević3, Herbert J. Meiselman4*, Oguz K. Baskurt1. The Effect of Alcohols on Red Blood Cell Mechanical Properties and Membrane Fluidity Depends on Their Molecular Size. PLOS ONE. September 2013.

35. Mirghania, Y.B. CheMana, ${ }^{*}$, S. Jinapb, B.S. Baharina, and J. Bakara.A New method for Determining Aflatoxins in Groundnut and Groundnut Cake Using Fourier Transform Infrared Spectroscopy with Attenuated Total Reflectance. M.E.S. JAOCS, Vol. 78, no. 10 (2001) 